\title{
Plexogenic pulmonary arteriopathy and liver cirrhosis
}

\author{
J R RÜTTNER, J-P BÄRTSCHI, R NIEDERMANN, AND J SCHNEIDER \\ From the Institute of Pathology, University of Zurich, Zurich, Switzerland
}

ABSTRACT Primary pulmonary hypertension with plexiform vascular changes in the lungs and liver cirrhosis is a rare combination of unclear pathogenesis. Until now, the real prevalence has not been known. The diagnosis of this association is usually made retrospectively. The criteria are morphological-that is, right ventricular hypertrophy and the characteristic pulmonary arterial lesions, as well as clinical-based on ECG and chest radiography. Between 1970 and 1977, two such cases have been found among a total of 11998 necropsies performed on adults. In the same necropsy series, 765 cases of liver cirrhosis were found. The prevalence of this combination is $0.26 \%$ of the cirrhosis and $0.016 \%$ of all necropsies of adults. This low prevalence raises serious doubts as to whether the association is more than coincidental.

There has been a growing interest in recent years in discovering non-haemodynamic causes of pulmonary hypertension. Of particular interest is the possibility that vasoactive agents may bypass the liver and damage the pulmonary vasculature. ${ }^{1}$ Although the association between chronic liver injury and pulmonary hypertension has been known for the past 30 years, ${ }^{2}$ there are no data to indicate whether this association is real or coincidental.

Since the epidemic of pulmonary hypertension in Switzerland, Austria, and Germany, ${ }^{3}$ we have paid particular attention to the occurrence of unexplained right ventricular hypertrophy and plexogenic pulmonary arteriopathy. We report here on the association between cor pulmonale, plexogenic arteriopathy, and liver cirrhosis in a large unselected series of necropsies, in order to provide the basis for future clinico-epidemiological studies on the pathogenesis of primary pulmonary hypertension.

\section{Methods}

Among 11998 necropsies of adults (older than 20 years) performed between 1970 and 1977 at the Institute of Pathology of the University Hospital of Zurich (95\% of all hospital deaths), there were

Address for reprint requests: Professor $J$ R Rüttner, Institute of Pathology, University of Zurich, Zurich, Switzerland.
765 cases of liver cirrhosis $(6 \cdot 3 \%)$. Two of these cases were associated with unexplained cor pulmonale and pulmonary plexiform arteriopathy.

Until 1975, right ventricular hypertrophy was diagnosed on the basis of macroscopic evaluation and measurement of myocardial thickness. ${ }^{4}$ Since 1975, the diagnosis has been made by calculating the ratio of the weight of the left ventricle and septum to that of the right ventricle ${ }^{5}$; a ratio of 2 or less is diagnostic of cor pulmonale.

Plexogenic pulmonary arteriopathy was characterised histologically by focal dilatation of muscular pulmonary arteries, $100-200 \mu \mathrm{m}$ in diameter, proliferation of endothelial cells with formation of anastomosing channels inside the vascular lumen, and concentric intimal fibrosis. ${ }^{6-8}$

\section{Case reports}

\section{CASE 1}

A 65-year-old man with a history of chronic alcoholism (one litre of wine a day) and decompensated liver cirrhosis was admitted to hospital with jaundice. He died a few days later because of massive gastrointestinal bleeding.

\section{Necropsy (AZ 97-71)}

Macroscopic examination revealed hepatic cirrhosis with small and large nodules (1550 g), oesophageal varices, erosive gastritis with massive 
haemorrhage, jaundice, right ventricular hypertrophy (heart weight: $450 \mathrm{~g}$ ), and focal bronchopneumonia.

Microscopically, the diagnosis of nodular cirrhosis with proliferation of bile ducts was confirmed. The most striking findings were in the pulmonary vessels. They consisted of two types of lesions: (1) muscular medial hypertrophy of the small arteries and concentric intimal thickening; (2) plexiform lesions (2-3 per $\left.\mathrm{cm}^{2}\right)$. No thromboembolism was identified in the lung.

\section{CASE 2}

A 62-year-old man was admitted to hospital because of liver cirrhosis, oesophageal bleeding, and ascites. He had a history of heavy alcohol intake, but no history of drug ingestion. Seven years before admission, he underwent splenectomy and cholecystectomy for hypersplenism. A liver biopsy (HZ 17577-70) at that time revealed annular cirrhosis with fatty changes and siderosis. At the time of admission, a chest radiograph showed two $2 \mathrm{~cm}$ round nodules in the left lung, cardiac enlargement and increased hilar markings.

Electrocardiogram revealed right ventricular hypertrophy and right bundle block. Laboratory findings disclosed pronounced anaemia, thrombocytopenia, raised $\mathrm{LDH}$, and a positive serum $\alpha$ fetoprotein. The patient died three weeks later. The clinical diagnosis was metastatic hepatoma and cor pulmonale. Heart catheterisation studies had not been performed.
Necropsy (AZ 660-77)

There was a large, partially necrotic tumour,음 $17 \mathrm{~cm}$ in diameter, in the left lobe of a cirrhotic liver, with invasion of the portal vein and met- $\mathbb{Q}$ astases in the right hepatic lobe. There weres haemorrhagic ascites (four litres), jaundice, andoesophageal varices with gastrointestinal haemor-? rhage. The heart weighed $540 \mathrm{~g}$. There was marked right ventricular hypertrophy. The weighte ratio between left and right ventricles was $1 \cdot 4 \cdot \overrightarrow{\vec{x}}$ Metastases were found in the lung.

Microscopic sections of the liver revealed hepa tocellular carcinoma and cirrhosis. Sections of the lung demonstrated in the small pulmonaryw arteries below $200 \mu \mathrm{m}$ all types of hypertensives changes, from muscular medial hypertrophy to intimal fibrosis, as well as plexiform lesions (fig). T) In some instances, tumour emboli were present.을 However, the plexogenic pulmonary arteriopathico changes were four times as frequent as the emboli.

\section{Discussion}

Plexiform pulmonary arteriopathy has been considered the hallmark of primary pulmonary hypertension. ${ }^{9}$ Although very characteristic for primary pulmonary hypertension, these anatomica $\frac{1}{2}$ changes are not pathognomonic and have been observed in pulmonary hypertension of known causes such as congenital cardiac left-right shunts, lung sequestration with arterial supply from theơ. aorta, and schistosomiasis. The association of

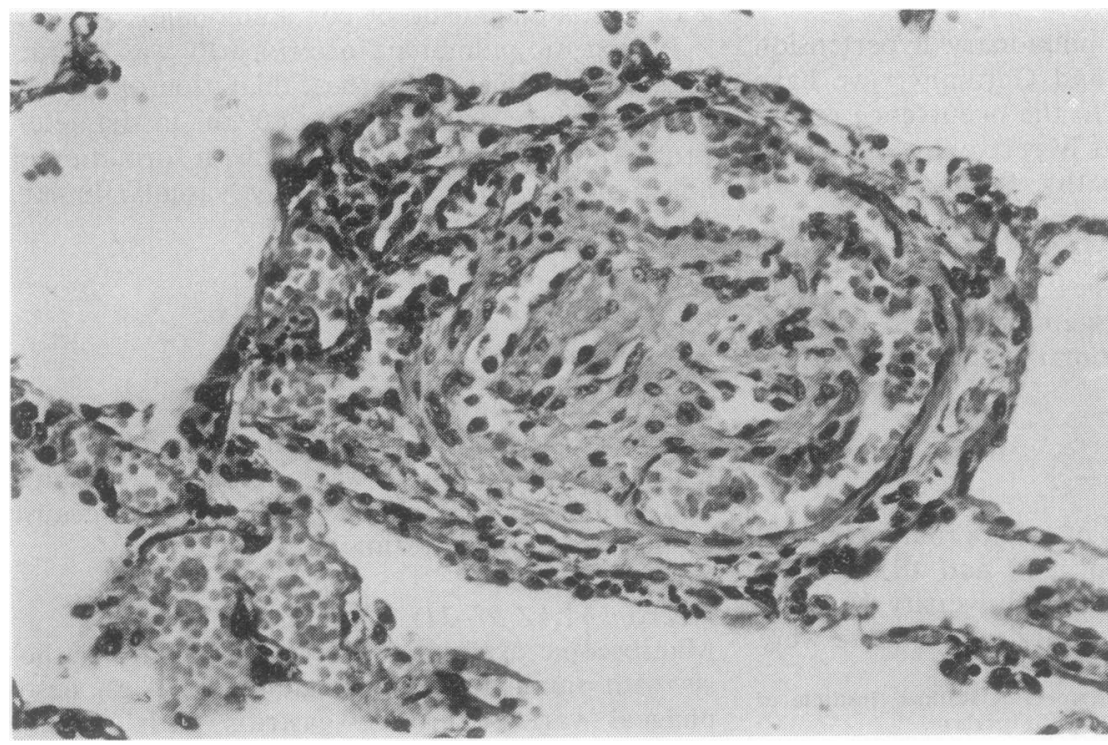

Figure Small pulmonary은 artery with plexiform le sions in case 2 ( $\times 250)$. 
plexiform lesions and cirrhosis of the liver is often cited in papers dealing with primary pulmonary hypertension. ${ }^{1011}$ The few pathological reports $^{72-15}$ do not give the incidence of this association. In 50 cases of cirrhosis studied in Liverpool, however, no pulmonary hypertension was found. ${ }^{16}$ Plexiform lesions may occur in patients with portal hypertension from portal thrombosis only, without concomitant cirrhosis. ${ }^{17}$

In our large necropsy series, only two cases of plexiform pulmonary arterial changes and right ventricular hypertrophy were found among 765 cases of liver cirrhosis (a prevalence of $0.26 \%$ ). In the same series, nine cases of plexiform pulmonary arteriopathy and cor pulmonale were observed. In eight cases, the disease was associated with the intake of an appetite-reducing drug. All nine patients with cryptogenic or drug-associated plexogenic arteriopathy were women (between 37 and 78 years).

In contrast, both cases of liver cirrhosis and pulmonary plexogenic arteriopathy were men (over 60 years). Both patients were alcoholics, had pronounced portal hypertension with oesophageal and gastric haemorrhage, and jaundice. In both cases, right ventricular hypertrophy was found at necropsy; in one, it was diagnosed before death. The plexiform lesions were not easily missed, since they were found in multiple areas of the lungs and did not differ from those encountered in congenital cardiac shunts. ${ }^{6}$ Signs of recurrent pulmonary thromboembolism were not present. The tumour emboli in case 2 were recent and represented terminal events; they could have accounted for the cardiac hypertrophy.

The mechanism of pulmonary hypertension associated with liver cirrhosis is poorly understood. Various pathogenic processes have been invoked. Naeye $^{12}$ suggested that, in most of the cases, the changes in the pulmonary vascular bed were the result of thromboemboli arising from the portal vein. Porta-pulmonary anastomoses have been demonstrated by Calabresi and Abelman ${ }^{18}$ through perigastric, perioesophageal, and mediastinal veins penetrating the pleura and draining lung capillaries, thus permitting microemboli to enter the lung. However, this does not explain the development of plexiform lesions in patients with liver cirrhosis but without portal thrombosis. Even in Naeye's material, ${ }^{12}$ portal thromboses were found in three cases only. Moreover, thromboemboli in pulmonary arteries can be distinguished microscopically from plexiform lesions. ${ }^{7}$

Haemodynamic disturbances, such as increased cardiac output and pulmonary blood flow in cirr- hosis, have been suggested but not proved as sufficient pathogenic factors ${ }^{1617}$ Lunseth et al ${ }^{19}$ demonstrated the lack of relationship between the severity of cirrhosis and the tendency to develop cor pulmonale in animal experiments as well as in humans. It was therefore suggested that the portal hypertension, rather than the cirrhosis per se, is of importance. ${ }^{17}$

In accordance with the experience in primary pulmonary hypertension, vasoconstriction of the small pulmonary arteries has been considered to be the initiating cause of pulmonary hypertension in liver cirrhosis. Wagenvoort and Wagenvoort ${ }^{720}$ believe that vasoconstriction leads to local endothelial lesions followed by thrombosis and finally organisation of the thrombi, which in turn lead to plexiform lesions. In this respect, dietary factors may be of importance. Metabolites escaping hepatic inactivation caused by cirrhosis may be responsible for the changes in lung vessels. ${ }^{17}$ Fish$\operatorname{man}^{1}$ favours the theory that plexiform lesions are the result of extreme bursts of pulmonary arterial hypertension, possibly induced by attacks of metabolically induced vasoconstriction.

Another mechanism is the possible effect of ingested substances normally inactivated by the liver. Pulmonary hypertension has been produced experimentally by feeding or injecting pyrrolizidine alkaloids. ${ }^{21-25}$ Whether genetic influences contribute to acquiring pulmonary hypertension in liver cirrhosis remains open. In children, our necropsy material over the last eight years has not shown any association between cirrhosis and pulmonary hypertension.

It is evident from our study that the combination of liver cirrhosis and pulmonary hypertension is exceptionally rare. It is, therefore, too early to exclude a coincidental association. Prospective clinicopathological investigations may prove helpful in elucidating this unsolved problem.

\section{References}

1 Fishman AP. Dietary pulmonary hypertension. Cir Res 1974; 35:657-60.

2 Mantz FA, Craige E. Portal axis thrombosis with spontaneous portacaval shunt and resulting cor pulmonale. Arch Pathol 1951; 52:91-7.

3 Gurtner HP, Gertsch M, Salzmann C, Stucki P, Wyss F. Häufen sich die primär vaskulären Formen des Cor pulmonale? Schweiz Med Wochenschr 1968; 98:1579-89, 1695-1707.

4 Vogt P, Rüttner JR. Das Cor pulmonale aus pathologisch-anatomischer Sicht; Ergebnisse einer Autopsiestatistik. Schweiz Med Wochenschr 1977; 107:549-53. 
5 Fulton R, Hutchinson EC, Jones AM. Ventricular weight in cardiac hypertrophy. Br Heart J 1952; 14:413-20.

6 Heath D, Edwards JE. The pathology of hypertensive vascular disease. A description of six grades of structural changes in the pulmonary arteries with special reference to congenital cardiac septal defects. Circulation 1958; 18:533-47.

7 Wagenvoort CA, Wagenvoort N. Hepatic injury of pulmonary hypertension. In: Pathology of pulmonary hypertension. New York: John Wiley, 1977: 95-102.

8 Spencer H. Chronic pulmonary hypertension. In: Spencer H (ed). Pathology of the lung. Third edition. Oxford: Pergamon Press, 1977: 579-648.

9 Hatano S, Strasser T, eds. Primary pulmonary hypertension. Report on a WHO Meeting, Geneva, 15-17 October 1973. Geneva: World Health Organisation, 1975; 7-45.

10 Edwards WD, Edwards JE. Recent advances in the pathology of pulmonary vasculature. In: Thurlbeck WM, Murray RA, eds. The lung structure, function and disease. Baltimore: Williams and Wilkins, 1978: 235-61.

11 Hanisch K. Introductory address-Symposium on vascular changes in pulmonary hypertension. Pathol Microbiol 1975; 43:235-6.

12 Naeye RL. "Primary" pulmonary hypertension with coexisting portal hypertension. A retrospective study of six cases. Circulation 1960; 22: 376-84.

13 Segel N, Kay JM, Bayley TJ, Paton A. Pulmonary hypertension with hepatic cirrhosis. Br Heart J $1968 ; 30: 575-8$.

14 Senior RM, Britton RC, Turino GM, Wood JA, Langer GA, Fishman AP. Pulmonary hypertension associated with cirrhosis of the liver and with portocaval shunts. Circulation 1968; 38:88-96.
15 Levine OL, Harris RC, Blanc WA, Mellins RBD Progressive pulmonary hypertension in childree with portal hypertension. J Pediatr 1973; 83 964-72.

16 Harris P, Heath D. The human pulmonary circula tion. Its form and function in health and disease? Second edition. Edinburgh: Churchill Livingstone $\vec{\oplus}$ 1977.

17 Heinemann O. Respiration and circulation inj patients with portal cirrhosis of the liver Circulation 1960; 22:154-9.

18 Calabresi, P, Abelmann WH. Portocaval anfi portopulmonary anastomoses in Laennec's cirrhosis and in heart failure. J Clin Invest 1957 36: $1257-65$.

19 Lunseth JH, Olmstead EG, Abboud F. A study of heart ddisease in one hundred and eight hospital= ized patients dying with portal cirrhosis. Archn Intern Med 1958; 102:405-13.

20 Wagenvoort CA, Wagenvoort N. Primary pul monary hypertension. A pathologic study of the lung vessels in 156 clinically diagnosed cases $\overrightarrow{.}$ Circulation 1970; 42:1163-84.

21 Lalich JJ, Merkow L. Pulmonary arteritis produced in rats by feeding Crotalaria spectabilis Lab Invest 1961; 10:744-50.

22 Kay JM, Heath D, Smith P, Bras G, Summeref J. Fulvine and the pulmonary circulation. Thora 1971; 26:249-61.

23 Kay JM, Smith P, Heath D. Aminorex and the pulmonary circulation. Thorax 1971; 26:262-70.

24 Heath D, Shaba J, Williams A, Smith P, Kombe A. A pulmonary hypertension-producing plan from Tanzania. Thorax 1975; 30:399-404.

25 Herget J, Paleček F. Experimental chronic pul monary hypertension. Int Rev Exp Pathol 1978 18:347-406. 